\title{
Demeclocycline in the treatment of the syndrome of inappropriate antidiuretic hormone release: with measurement of plasma ADH
}

\author{
P. L. PADFIELD \\ M.B., M.R.C.P.
}

G. P. HodsMan

M.B., M.R.C.P.

\author{
J. J. MORTON \\ Ph.D.
}

MRC Blood Pressure Unit and Department of Medicine, Western Infirmary, Glasgow G11 6NT

\begin{abstract}
Summary
A patient with the syndrome of inappropriate antidiuretic hormone release (SIADH) following head injury and meningitis was studied during treatment with demeclocycline, a drug known to produce a reversible nephrogenic diabetes insipidus. No changes were observed during six days of demeclocycline $1200 \mathrm{mg} / 24 \mathrm{hr}$ but urine output increased significantly, with the production of a dilute urine, when the dose was increased to $2400 \mathrm{mg} / 24 \mathrm{hr}$. The patient lost weight, and all biochemical features of the syndrome were rapidly corrected despite an unchanged fluid intake and despite the persistence of high plasma levels of ADH. The rise in serum sodium was accompanied by mild sodium retention, as measured by external balance and exchangeable sodium.

A complication of treatment was the development of acute renal failure possibly induced by a nephrotoxic effect of high circulating levels of demeclocyline. On stopping demeclocyline renal function returned to normal and, after some delay, SIADH returned, and was still present 9 months after initial presentation. This confirms earlier reports of the efficacy of demeclocycline in SIADH; but the authors advise caution against increasing the dose above $1200 \mathrm{mg} /$ $24 \mathrm{hr}$.
\end{abstract}

\section{Introduction}

Fluid restriction, the conventional therapy for the syndrome of inappropriate antidiuretic hormone secretion (SIADH) (Bartter and Schwartz, 1967) can be irksome and requires close supervision of fluid intake. Both lithium carbonate (Singer, Rotenberg and Puschett, 1972) and demeclocycline (White and Fetner, 1975; De Troyer and Demanet, 1975; Therrill et al., 1975; Cledes, Clavier and Kerbrat, 1976; Perks, Mohr and Liversedge, 1976) have been shown to be effective in the treatment of SIADH in a small number of patients. It has been possible to study, in detail, the effects of demeclocycline on

Requcsts for reprints to: Dr Paul L. Padfield, Western Infirmary, Glasgow, G11 6NT. fluid and electrolyte balance in a patient with SIADH following head injury and meningitis, together with serial measurements of plasma ADH.

\section{Case history}

A 64-year-old male was admitted to hospital, 4 days following a head injury, with a story of progressive confusion. A clinical diagnosis of meningitis was confirmed by the finding of an increased cell count in the cerebrospinal fluid with pneumococci on direct film and grown on culture. He was started on penicillin and sulphadimidine and 12 days later was much improved. On admission his serum sodium had been $139 \mathrm{mmol} / \mathrm{l}$ with a blood urea of $5.1 \mathrm{mmol} / \mathrm{l}$ and 12 days later $133 \mathrm{mmol} / \mathrm{l}$ and 2.9 $\mathrm{mmol} / \mathrm{l}$ respectively. Skull radiology revealed an occipital fracture but chest X-rays were persistently normal. Seventeen days after admission he was discharged although his serum sodium at that time was $128 \mathrm{mmol} / \mathrm{l}$. He was re-admitted one week later grossly confused with no focal neurological signs. A repeat lumbar puncture was normal but his serum sodium had fallen to $112 \mathrm{mmol} / \mathrm{l}$. On the day after admission, serum sodium was $108 \mathrm{mmol} / \mathrm{l}$ with a plasma osmolality of $219 \mathrm{mosmol} / \mathrm{kg}$ with a concurrent urine osmolality of $473 \mathrm{mosmol} / \mathrm{kg}$. Plasma ADH was elevated at $9 \mathrm{pg} / \mathrm{ml}$ (normal range 4-8 $\mathrm{pg} / \mathrm{ml})$; clearly inappropriate for the plasma osmolality. Fluid restriction resulted in a rise of serum sodium to $136 \mathrm{mmol} / \mathrm{l}$ with a parallel improvement in clinical state. He was discharged from hospital with advice to restrict his fluid intake but serum sodium fell again to $126 \mathrm{mmol} / \mathrm{l}$. He was readmitted 3 months after his initial presentation for assessment of the effects of demeclocycline.

\section{Special studies}

The patient was admitted to a metabolic ward and placed on a fixed normal intake of sodium (133 $\mathrm{mmol} / 24 \mathrm{hr}$ ) and potassium $(53 \mathrm{mmol} / 24 \mathrm{hr})$. Fluid intake was arbitrarily fixed at $2000 \mathrm{ml} / 24 \mathrm{hr}$ (a volume designed to ensure the presence of SIADH). During 


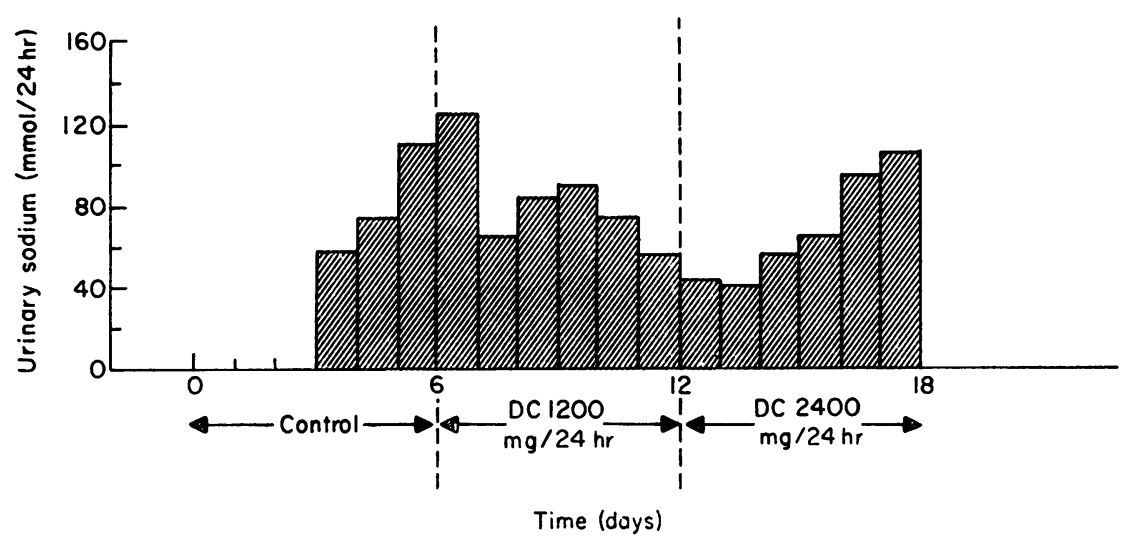

FIG. 1. Effect of demeclocycline (DC) on urinary sodium in the syndrome of inappropriate antidiuretic hormone release (SIADH).

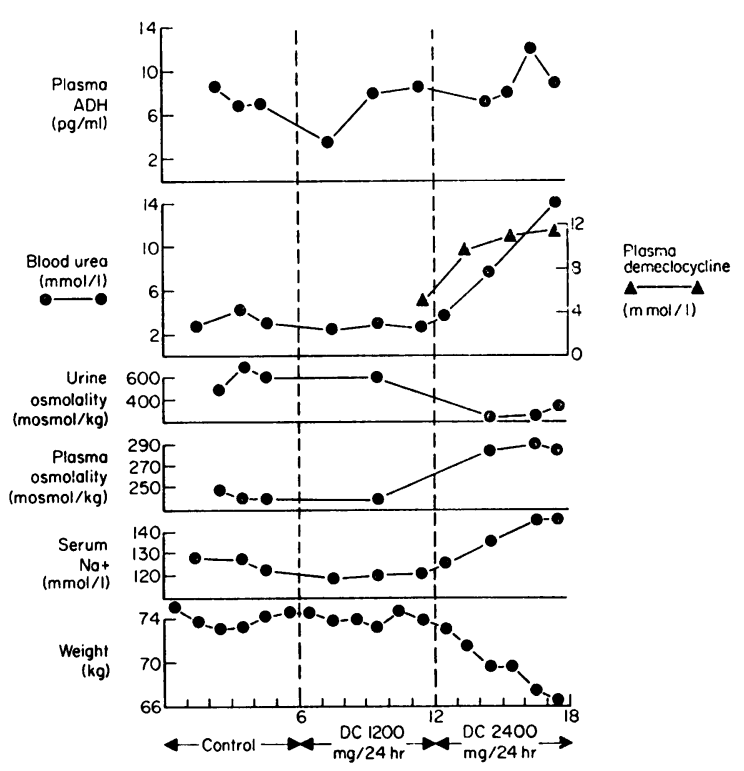

FIG. 2. The effects of demeclocycline (DC) in the syndrome of inappropriate antidiuretic hormone release (SIADH).

an initial run-in period of 6 days, serial measurements were made of weight, serum electrolytes (routine automated analysis), fluid and electrolyte balance, exchangeable sodium and potassium (Davies and Robertson, 1973) and urine and plasma osmolality by freezing point depression (Advanced Osmometer). Plasma ADH was measured by radioimmunoassay (Morton, Padfield and Forsling, 1975). The patient then received demeclocycline (Ledermycin $\left.{ }^{\circledR}\right) 300 \mathrm{mg}$ six-hourly for 6 days followed by $600 \mathrm{mg}$ six-hourly for a further 6 days. Changes in the above measurements were noted. Plasma levels of demeclocycline were measured using gas-liquid o chromatography (quoted antibacterial range 3-5 $\mu \mathrm{g} / \mathrm{ml})$.

\section{Results of special studies}

Fluid balance (Fig. 1)

During the initial run-in period, urine output wass fairly constant and averaged $1333 \mathrm{ml} / 24 \mathrm{hr}$. The mean early morning urine osmolality was $60 \overrightarrow{0}$ mosmol/kg. During the first day of demeclocycline. therapy urine output increased to $2200 \mathrm{ml}$ althougt the osmolality was not measured. Thereafter, urine output fell, giving a mean daily output of $1590 \mathrm{ml}$ during the 6 days of the lower dose of demeclocycline. The mean early morning urine osmolality during this period was $600 \mathrm{mosmol} / \mathrm{kg}$. On increasing the $\varrho$ dose of demeclocycline to $2400 \mathrm{mg} / 24 \mathrm{hr}$ a diuresis $\overrightarrow{\vec{O}}$ occurred with a daily urine output averaging 23633 $\mathrm{ml}$ (osmolality $266 \mathrm{mosmol} / \mathrm{kg}$ ). As fluid intake and $\rightleftharpoons$ ambient temperature were constant, this represents? a true fluid loss and was accompanied by a dramatic $\overline{0}$ fall in weight (Fig. 2).

\section{Sodium balance (Fig. 2 and 3)}

Serum sodium remained low during the run-in $\frac{2}{3}$ period and during the first 6 days of demeclocycline ${ }_{\circ}$ treatment. Thereafter serum sodium and plasma osmolality rose rapidly to normal (Fig. 2). During $\frac{7}{0}$ the run-in period exchangeable sodium was 2860 . mmol and exchangeable potassium $2846 \mathrm{mmol}$. At $\stackrel{\sim}{\circ}$ the end of the study exchangeable sodium had in- N creased to $2957 \mathrm{mmol}$ and potassium had remained $\mathrm{N}$ unchanged at $2848 \mathrm{mmol}$. Urine samples for elec- $\mathcal{W}$ trolyte measurement were lost during the first 3 days of the study but the net balance during the remaining 3 days of the run-in period and the first $\stackrel{\Phi}{\oplus}$ 6 days of demeclocycline therapy was constant, averaging an apparent positive balance of 53 and 


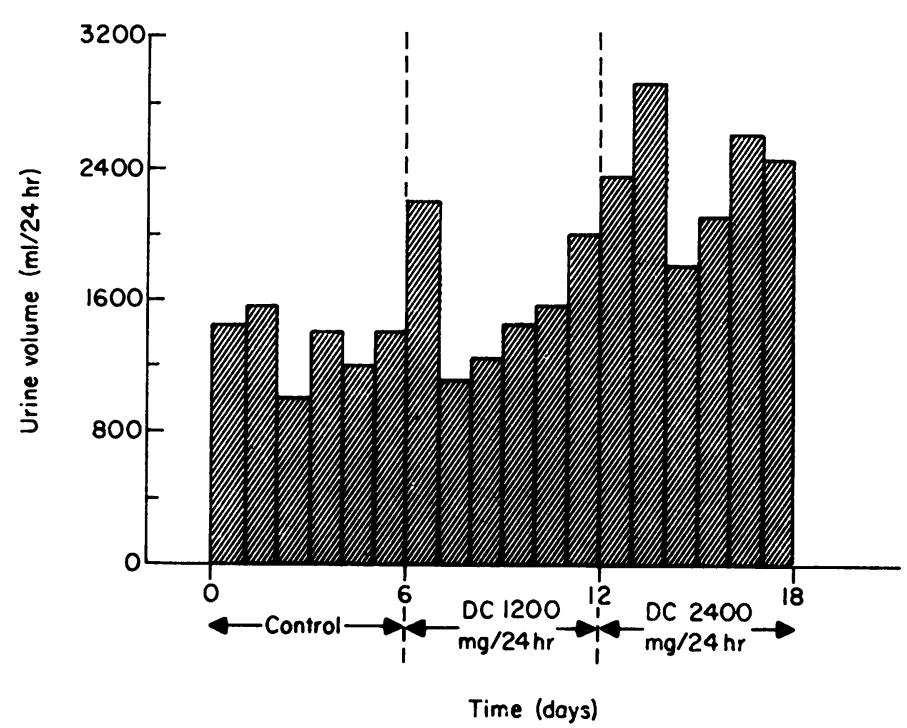

FIG. 3. The effect of demeclocycline (DC) on urine output in the syndrome of inappropriate antidiuretic hormone release (SIADH).

$51 \mathrm{mmol} / 24 \mathrm{hr}$ respectively. During the last 6 days of the study there was initially sodium retention so that the average positive balance was $68 \mathrm{mmol} / 24 \mathrm{hr}$ : a net increase of $16 \mathrm{mmol} / \mathrm{day}$ over the earlier periods. This represents a total gain of $96 \mathrm{mmol}$ over the 6-day period (tallying well with exchangeable sodium). There was no significant change in either serum potassium or external potassium balance.

\section{Antidiuretic hormone}

With the exception of one value of $3.6 \mathrm{pg} / \mathrm{ml}$ on the first day of demeclocycline therapy ADH levels remained high throughout the study (Fig. 2) with a probable slight increase at the end of the study.

\section{Renal function}

During the phase of acute diuresis, renal function deteriorated rapidly, creatinine clearance falling from a mean of $123 \mathrm{ml} / \mathrm{min}$ during the first 12 days to $34 \mathrm{ml} / \mathrm{min}$ at the end of the study when demeclocycline therapy was discontinued (Fig. 2).

\section{Blood levels of demeclocycline}

Plasma demeclocycline increased rapidly during the second period of administration of the drug from $4.5 \mu \mathrm{g} / \mathrm{ml}$ at the end of the $1200 \mathrm{mg}$ period to a peak of $11.9 \mu \mathrm{g} / \mathrm{ml}$ (Fig. 2).

\section{Subsequent course}

The patient rapidly recovered following the cessation of demeclocycline and over the following 2 weeks blood urea urea fell to $3 \mathrm{mmol} / \mathrm{l}$ and creati- nine clearance increased to $98 \mathrm{ml} / \mathrm{min}$. Serum sodium remained above $135 \mathrm{mmol} / \mathrm{l}$ for approximately two months and then gradually fell over a period of three months to stabilize at about $126 \mathrm{mmol} / 1$ with a plasma osmolality of $260 \mathrm{mosmol} / \mathrm{kg}$ and urine osmolality of $570 \mathrm{mosmol} / \mathrm{kg}$. Despite this, he has remained well with no complaints and chest X-ray has been repeatedly negative. His migration abroad has precluded further study.

\section{Discussion}

SIADH in this man was related to head injury and subsequent meningitis and this seems the likely aetiology (Bartter and Schwartz, 1967). The duration of the syndrome is rather long, however, and the possibility of an occult neoplasm must continually be borne in mind. Fluid restriction proved difficult and another form of treatment was clearly desirable.

Demeclocycline produces a predictable, reversible and dose-dependent nephrogenic diabetes insipidus (Singer and Rotenberg, 1973) unlike lithium carbcnate whose effect on renal function is variable (Forrest et al., 1974; Padfield et al., 1977). It has been claimed that while tetracyclines in general (Shils, 1963) and outdated tetracyclines in particular (Gross, 1963) can be nephrotoxic the renal effects of demeclocycline are confined to an impairment of concentrating ability (Wilson et al., 1973). Castell and Sparks (1965) were the first to describe this peculiar property of demeclocycline, and their initial observations have since been confirmed (Singer and Rotenberg, 1973; Wilson et al., 1973; Maxon and Rutsky, 1973; Hayek and Ramirez, 
1974; Miller and Palo, 1974). The mode of action of demeclocycline in producing nephrogenic diabetes insipidus is complex as both ADH- (Singer and Rotenberg, 1973; Feldman and Singer, 1974) and cyclic AMP- (Singer and Rotenberg, 1973; Dousa and Wilson, 1974) mediated effects on water transport can be separately affected. In the light of these findings it was logical to try the effect of the drug in the treatment of SIADH and it has been shown to be effective in a small number of cases (De Troyer and Demanet, 1975; Cherrill et al., 1975; Cledes et al., 1976; Perks et al., 1976). The initial dose of $1200 \mathrm{mg}$ was chosen for the present case as this has been shown to be invariably effective in normal subjects (Singer and Rotenberg, 1973). Although the time of onset of response to demeclocycline is variable ranging from as little as 6-8 $\mathrm{hr}$ (Maxon and Rutsky, 1973) to as long as 4 weeks (Miller and Palo, 1974), the dose was increased after one week in order to ensure a response within the time of the study. In retrospect, it is clear that $2400 \mathrm{mg} / 24 \mathrm{hr}$ was an excessive dose because, although the patient rapidly corrected all biochemical abnormalities (large volumes of dilute urine were passed, sodium was retained, serum sodium rose to high normal values and weight was lost), renal failure ensued. While there may have been a pre-renal element it is possible that the high plasma levels of demeclocycline were nephrotoxic. Recovery was, however, rapid and complete. Nephrotoxicity has recently been reported with the use of demeclocycline in cirrhosis with ascites (De Troyer et al., 1976; Oster, Epstein and Ulano, 1976) and in cardiac failure (Cox et al., 1977).

\section{Sodium balance in SIADH}

Mild sodium depletion has often (Schwartz et al., 1957; Padfield, et al., 1976; Schwartz, Tassel and Bartter, 1960; Nolph and Schrier, 1970) but not invariably (Jones et al., 1968; Barraclough, 1971) been described in SIADH. The modest sodium gain observed in the present patient (both on external balance and total exchangeable sodium results) is somewhat less than had previously been seen by the authors in this syndrome corrected by simple fluid deprivation (Padfield et al., 1976) and may be explained by the observation that tetracyclines can be natriuretic (Shils, 1963), and that demeclocycline increases urinary sodium when used to treat the water retention of cirrhotics with ascites (De Troyer et al., 1976; Oster et al., 1976).

\section{Antidiuretic hormone}

So far as the authors know, this paper represents the first report of measurement of antidiuretic hormone levels during treatment with demeclocycline in a patient with clearly documented SIADH.
Plasma levels of ADH vary widely in SIADH and $\underset{\varnothing}{\overparen{2}}$ extremely high values are not always seen (Padfield $\stackrel{\varnothing}{ }$ et al., 1976). The patient clearly had an inappro-. priately high plasma ADH at a time when his plasma $\stackrel{\vec{F}}{\overrightarrow{2}}$ was dilute. With the exception of one value during the study, ADH levels remained high throughout, $\frac{\bar{\sigma}}{\circ}$ clearly showing that correction of the syndrome was $\overline{\bar{N}}$. not due to a spontaneous recovery. There was $a \vec{\mathbb{}}$ slight tendency for ADH to rise towards the end of $\propto$ the period of treatment and the significance of this ${ }^{\circ}$ observation has already been discussed (Padfield $\overrightarrow{0}$ et al., 1976).

In conclusion, the effectiveness of demeclocycline $\vec{\sigma}$ in correcting the biochemical abnormalities of SIADH in the presence of high circulating levels of $\frac{0}{3}$ ADH has been demonstrated. In the dosage used in this study there was possible evidence of nephro- + toxicity and the future use of the drug will need to be confined to smaller doses. Clearly, demeclocycline represents an important advance in the treatment of $\mathrm{C}^{\mathrm{N}}$ syndrome of inappropriate antidiuretic hormone 0 release.

\section{References}

BARRAClOUgh, M.A. (1971) Inappropriate secretion $9 \mathrm{gf}$ antidiuretic hormone and potassium depletion. Proceedings of the Royal Society of Medicine, 64, 1069.

BARTTER, F.C. \& Schwartz, W.B. (1967) The syndrome ${ }^{\circ} \overrightarrow{0}$ inappropriate secretion of antidiuretic hormone. Americ Journal of Medicine, 42, 790.

Castell, D.O. \& SParks, H.A. (1965) Nephrogenic diabetes insipidus due to demethychlortetracycline hydrochloride. Journal of the American Medical Association, 193, 137.

Cherrill, D.A., Stote, R.M., Birge, J.R. \& Singer, I. (1975) Demeclocycline treatment in the syndrome of in- 응 appropriate antidiuretic hormone secretion. Annals of $\propto$ Internal Medicine, 83, 654.

Cledes, J., Clavier, J. \& Kerbrat, G. (1976) Treatment of inappropriate antidiuresis syndrome with demethylchloretetracycline. Nouvelle Presse Médicale, 5, 1308.

Cox, M., Guzzo, J., Morrison, G. \& Singer, I. (1977) Demeclocycline and therapy for hyponatremia. Annals of $\overline{0}$ Internal Medicine, 86, 113.

Davies, D.L. \& Robertson, J.W.K. (1973) Simultaneous measurement of total exchangeable potassium and sodium 3 using ${ }^{43} \mathrm{~K}$ and ${ }^{24} \mathrm{Na}$. Metabolism, $22,133$.

De Troyer, A. \& Demanet, J.C. (1975) Correction of anti- 응 diuresis by demecylocycline. New England Journal of Medicine, 293, 915.

De Troyer, A., Pilly, W., Broeckaert, I. \& Demanet, 을 J.C. (1976) Demeclocycline treatment of water retention $D$ in cirrhosis. (Correspondence) Annals of Internal Medicine, 85, 336.

DousA, T.P. \& WiLson, D.M. (1974) Effects of demethyl- స chlortetracycline on cellular action of antidiuretic hormone $N$ in vitro. Kidney International, 5, 279.

Feldman, H.A. \& Singer, I. (1974) Comparative effects of $N$ tetracyclines on water flow across toad urinary bladders. $\sigma$ Journal of Pharmacology and Experimental Therapeutics, $190,358$.

Forrest, J.N., Cohen, A.D., Torretti, J., Himmelhoch, $\frac{\bar{D}}{\mathbb{D}}$ J.M. \& EPSTEIN, F.H. (1974) On the mechanism of lithium- ? induced diabetes insipidus in man and the rat. Journal of $\square$ Clinical Investigation, 53, 1115. 
Gross, J.M. (1963) Fanconi syndrome (adult type) developing secondary to the ingestion of outdated tetracycline. Annals of Internal Medicine, 58, 523.

Hayek, A. \& RamiRwz, J. (1974) Demeclocycline-induced diabetes insipidus. Journal of the American Medical Association, 229, 676.

Jones, N.F., Barraclough, M.A., Forsling, M.L. \& PETCH, C.P. (1968) Inappropriate production of vasopressin, potassium deficiency and cerebrovascular disease. American Journal of Medicine, 45, 474.

MAXON, H.R. \& RUTSKY, E.A. (1973) Vasopressin-resistant diabetes insipidus associated with short-term demethylchlortetracycline (declomycin) therapy. Military Medicine, 138, 500.

Miller, E.E. \& Palo, T.A. (1974) Nephrogenic diabetes insipidus secondary to declomycin. Arizona Medicine, 31, 24.

Morton, J.J., Padfield, P.L. \& Forsling, M.L. (1975) A radio-immunoassay for plasma arginine vasopressin in man and dog: Application to physiological and pathological states. Journal of Endocrinology, 65, 511.

NolPH, K.D. \& SCHRIER, R.W. (1970) Sodium, potassium and water metabolism in the syndrome of inappropriate antidiuretic hormone secretion. American Journal of Medicine, 49, 534.

OSTER, J.R., EpSTein, M. \& Ulano, H.B. (1976) Deterioration of renal function with demeclocycline administration. Current Therapeutic Research, 20, 794.

PAdfield, P.L., Morton, J.J., Brown, J.J., LeVer, A.F., Robertson, J.I.S., Wood, M. \& Fox, R. (1976) Plasma arginine vasopressin in the syndrome of antidiuretic hormone excess associated with bronchogenic carcinoma. American Journal of Medicine, 61, 825.
Padfield, P.L., Park, S.J., Morton, J.J. \& Braidwood, A.E. (1977) Plasma levels of antidiuretic hormone in patients receiving prolonged lithium therapy. British Journal of Psychiatry, 130, 144.

Perks, W.H., Mohr, P. \& Liversedge, I.A. (1976) Demeclocycline in inappropriate ADH syndrome. Lancet, ii, 1414.

Schwartz, W.B., Bennet, W., Curelop, S. \& Bartter, F.C. (1957) A syndrome of renal sodium loss and hyponatremia probably resulting from inappropriate secretion of antidiuretic hormone. American Journal of Medicine, 23, 529.

Schwartz, W.B., Tassel, D. \& Bartter, F.C. (1960) Further observations on hyponatremia and renal sodium loss probably resulting from inappropriate secretion of antidiuretic hormone. New England Journal of Medicine, 262, 743 .

SHILS, M.E. (1963) Renal disease and the metabolic effects of tetracycline. Annals of Internal Medicine, 58, 389.

Singer, I. \& Rotenberg, D. (1973) Demeclocycline-induced nephrogenic diabetes insipidus. Annals of Internal Medicine, 79, 679.

Singer, I., Rotenberg, D. \& Puschett, J.B. (1972) Lithium:induced nephrogenic diabetes insipidus: In vivo and in vitro studies. Journal of Clinical Investigation, 51, 1081.

White, M.G. \& Fetner, C.D. (1975) Treatment of the syndrome of inappropriate secretion of antidiuretic hormone with lithium carbonate. New England Journal of Medicine, 292, 390.

Wilson, D.M., Perry, H.O., Sams, W.M. \& Dousa, T.P. (1973) Selective inhibition of human distal tubular function by demeclocycline. Current Therapeutic Research, 15 (10), 734. 